\title{
THE EARLY PRECLASSIC OBSIDIAN INDUSTRY OF PASO DE LA AMADA, CHIAPAS, MEXICO
}

\author{
John E. CLARK \\ New World Archaeological Foundation
}

\section{Introduction}

This paper differs from previous descriptions of Mesoamerican obsidian in that a simple flake industry rather than a blade industry is reported. Flake industries have been noted in many parts of Mesoamerica for the Early Preclassic period (Boksenbaum, 1978; Cobean et al., 1971; Coe, 1961; Coe and Flannery, 1967; Ceja, 1978; Grove, 1971: 40; Green and Lowe, 1967; Lowe, 1975; MasNeish et al., 1967; Niederberger, 1976; Pires-Ferreira, 1976: 309; Zeitland, 1978, 1979), but to date only one attempt has been made to describe these in detail (Boksenbaum, 1980). The purpose of this study is to present another description of an Early Preclassic flake industry. The descriptive format differs significantly from that recently proposed by Boksenbaum (1980) and follows instead the principles of behavioral typology (Collins, 1975; Sheets, 1975) in defining the obsidian industry. The obsidian industry is described in the first section. Following this descriptive section are brief discussions on techniques, as evidenced in the artifacts, and an analysis of the imported obsidian commodities.

The artifacts described below come from the Early Preclassic site of Paso de la Amada, which is located on the Pacific Coast of Chiapas; (see Figure 1). They date to the Barra and Ocos phases or approximately 1800-1500 B. C. (Lowe, 1978). The prevalence of small obsidian chips in Early Preclassic deposits has previously been reported for this area (Coe, 1961; Coe and Flannery, 1967; Green and Lowe, 1967; Lowe, 1975; Zeitland, 1979). It has further been postulated that these small pieces of obsidian were part of manioc grating boards (Green and Lowe, 1967; Lowe, 1975, see Davis, 1975, and Zeitland, 1979 for critiques of this hypothesis). Because of the hypothesized importance 


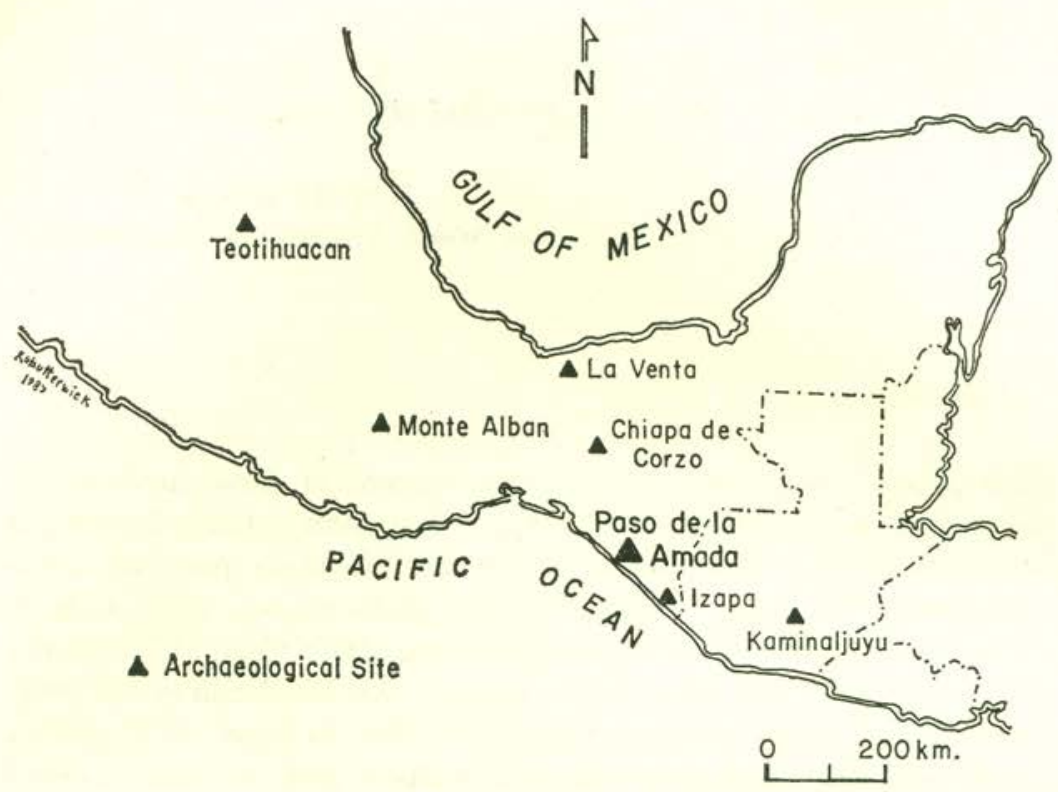

Figure 1. General map of Southern Mesoamerica showing the location of Paso de' la Amada in relation to other better-known sites. 
of these obsidian chips a special effort was made during the New World Archaeological Foundation's investigations at Paso de la Amada to collect even the smallest pieces. The following description of the Early Preclassic industry of Paso de la Amada is based upon a preliminary study of this material.

\section{Artifacts}

The collection of obsidian from Paso de la Amada numbers 16627 pieces. In 1977 an initial attempt was made to classify a large sample (13 877 pieces) of these obsidian artifacts. After many hours of frustration the author understood why such collections have been categorized as amorphous or non-descript flakes by previous researchers. It was extremely difficult to find meaningful variation among the flakes and debitage. These difficulties probably account for the present paucity of such studies in Mesoamerica. Two categories did stand out, however, but were of unknown significance. Subsequent analysis of other obsidian collections, reading, and experimentation eventually lead to the identification of these pieces as bipolar cores and flakes. After these unique artifacts had been recognized another sample of obsidian from Paso de la Amada numbering 2074 pieces was analyzed. In the second analysis the portion of obsidian that had not been studied previously was examined. The identified number of each of the artifact types shown in Table 1 is based upon the second study.

The obsidian industry of Early Preclassic Paso de la Amada is extremely simple compared to Mesoamerican blade technologies of later periods. During the Early Preclassic the desired end products were small flakes which could be used without further modification in a multitude of ways. The behavioral structure of this industry is shown in Figure 2. Basically, the industry involved two major steps: first, the percussion manufacture of small usable flakes from a spall, and second, the production of flakes by the bipolar technique from otherwise expended casual cores, chunks, or even larger flakes. Debitage in the form of flake shatter, chunks (or core shatter), and unidentified pieces resulted from both these steps.

Flakes are identified by the presence of positive bulbs of force; fragments which lack the bulb are flake shatter. At least two types of flakes are present in the Early Preclassic sample: 1) percussion flakes and 2) bipolar flakes. ${ }^{*}$ As the names suggest, these are flakes produced

* Bipolar flakes are not to be confused with lascas bipolares as defined by Mirambell (1974). The equivalent to her lascas biopolares would be didirectional flakes. The terminological confusion is unfortunate. 


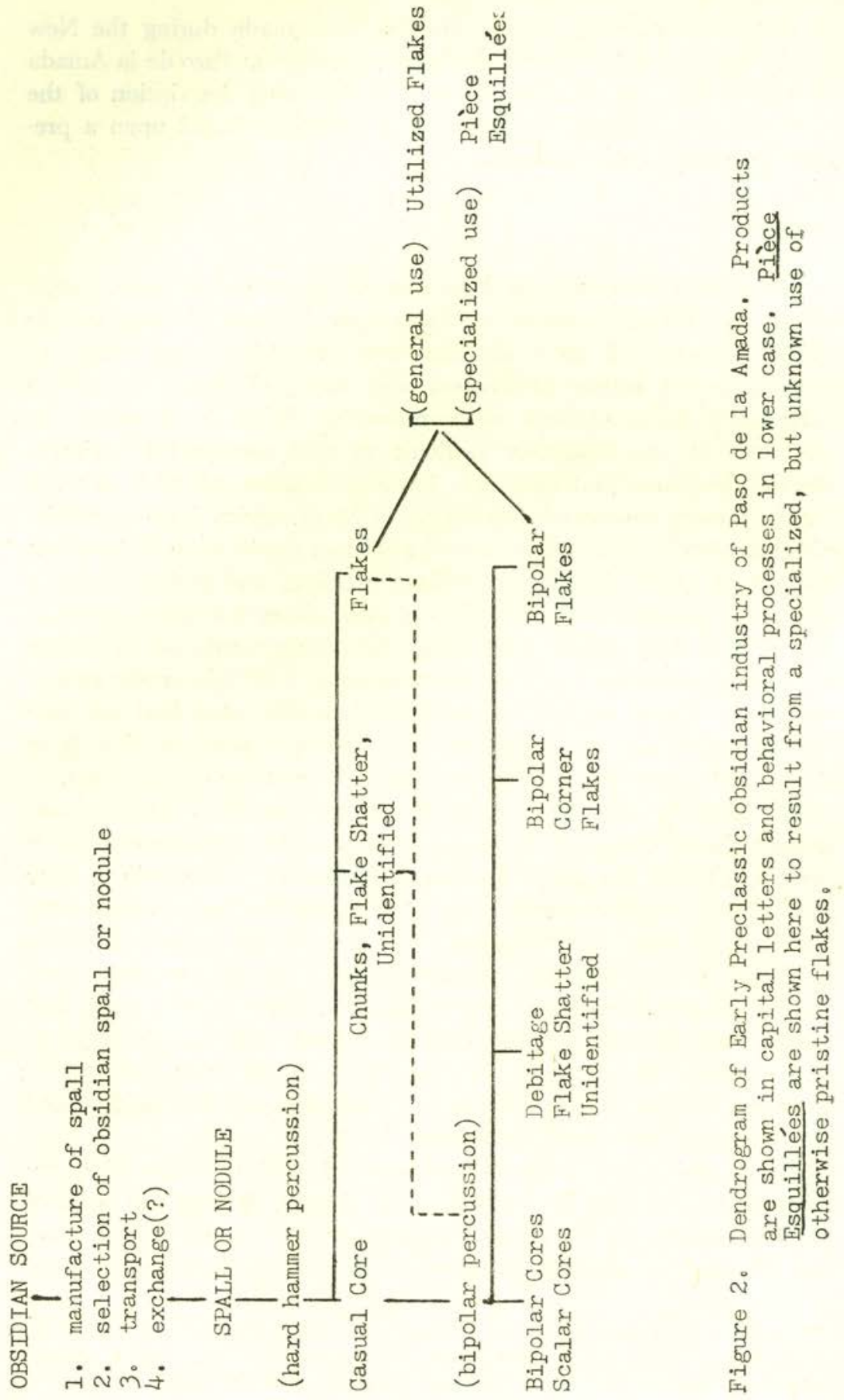

Estudios de Cultura Maya. Vol. XIII, 1981

Instituto de Investigaciones Filológicas/

Centro de Estudios Mayas, UNAM

http://www.iifilologicas.unam.mx/estculmaya/ 


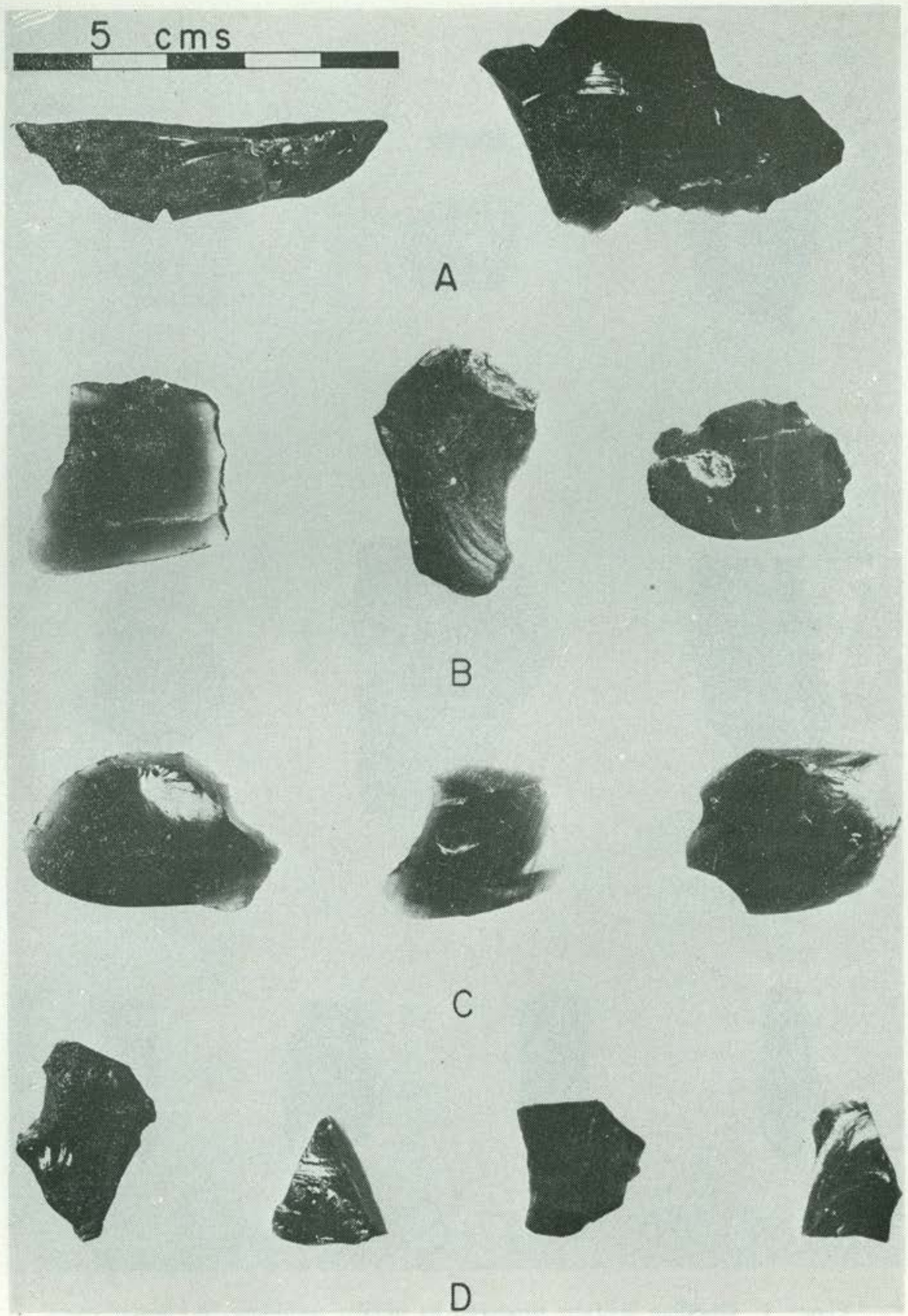

Figure 3. Obsidian artifacts produced by percussion. A - Two views of a casual core; B - Dorsal views of percussion flakes; C - Ventral views of percussion flakes; D - Small Estudios de Cultura Maya. Vohwmiks 1asgd flake shatter. Instituto de Investigaciones Filológicas/ Centro de Estudios Mayas, UNAM http://www.iifilologicas.unam.mx/estculmaya/ 

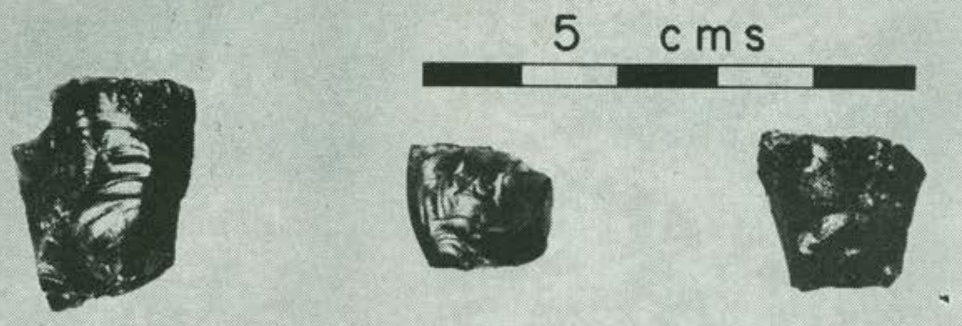

A
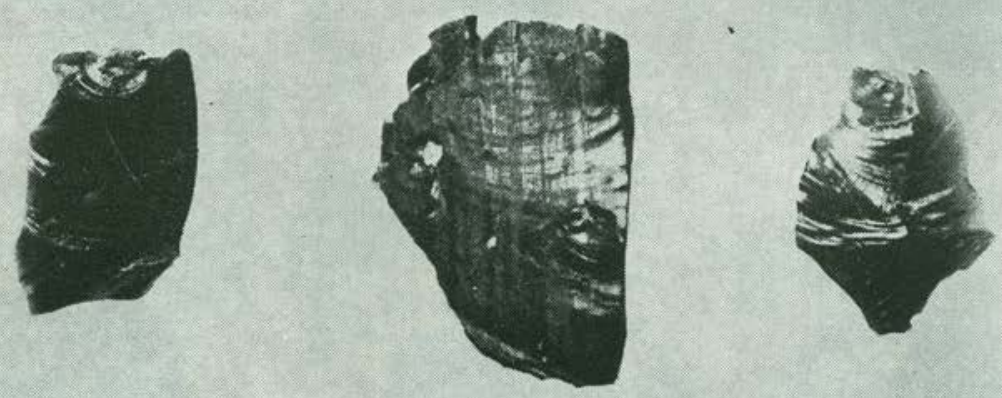

I

B
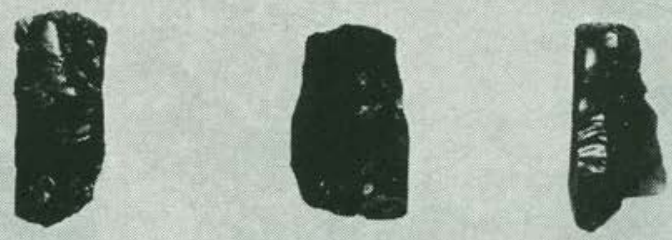

C

Figure 4. Obsidian artifacts produced by bipolar technique. A-Scalar cores; B - Ventral view of large bipolar flakes; C-Bipolar corner flakes.

Estudios de Cultura Maya. Vol. XIII, 1981

Instituto de Investigaciones Filológicas/

Centro de Estudios Mayas, UNAM

http://www.iifilologicas.unam.mx/estculmaya/ 
by (1) direct percussion or (2) bipolar percussion respectively. In some instances it is difficult to distinguish between the two flake types because some percussion flakes were removed with a blow which was delivered at a $90^{\circ}$ angle to the platform of the spall core. Such a blow closely duplicates that of the bipolar technique, where a stone anvil support is also used. Most of the direct percussion flakes have large platforms as well as very noticeable ring cracks and prominent bulbs of percussion which result from the use of a sharp indentor (a round hammerstone of quartzite or other hard metamorphic stone). Most have well-defined waves emanating out from the point of impact (see Figure $3 \mathrm{~B}, \mathrm{C}$ ). The resultant flakes are wider than long, usually have hinge terminations, and are generally conch-shaped. On the other hand, bipolar flakes have no obvious platform and no bulb of percussion. Instead, a knife-like edge is characteristic of the platform area because the platform is sheared or shattered. The bipolar technique splits the "cone of force" and therefore leaves a flat surface instead of a bulb on a flake's ventral surface (Crabtree, 1972). However, very visible, but lacking significant micro-topography, concentric waves radiate out from the point of impact. In many instances both the distaI and proximal ends of the flake evidence crushing and shattering from direct impact from the hammerstone and the anvil (Figure 4B).

A core is defined simply as a stone from which man-made flakes have been removed. Detaching flakes by direct percussion results in a percussion core. Similarly, a bipolar core is formed by splitting off bipolar flakes. Early Preclassic percussion cores are termed "casual cores" (Tolstoy, 1971) or cores from which flakes have been removed at various angles according to convenience or expedience rather than design. By definition, then, there is no common shape of expended casual cores; they are amorphous lumps evidencing scars of numerous flake removals from all sides and from numerous angles (see Figure $3 \mathrm{~A})$. This is not the case, however, for most of the bipolar cores.

In this study a distinction has been made between bipolar cores and scalar cores. As used here a scalar core (White, 1968) is an expended bipolar core and therefore a specific type of bipolar core. Scalar cores are usually square or nearly so in plain view and lenticular in both cross-sections. Other characteristics are their small size and bifacial scarring. In fact, these cores appear to be very small square bifaces (these may have been referred to by Coe and Flannery [1967] and Green and Lowe [1967] as thumbnail scrapers). A major distinguishing feature is again the matched sets of crushed edges, either two or all four (see Figure 4A). Non-exhausted bipolar cores are simply pieces of obsidian from which bipolar flakes have been removed. Since they 
are not exhausted they are of many different shapes and sizes. "Bipolar cores" as used in Figure 2 and Table 1 refer to these nonexhausted specimens. Therefore, as used here the categories are mutually exclusive. The term "bipolar cores" when used generically refers to both bipolar cores and scalar cores.

TABLE 1

ARTIFACT FREQUENCIES FROM PASO DE LA AMADA, CHIAPAS, MEXICO

\begin{tabular}{lrr}
\hline Artifact Type & \multicolumn{1}{c}{$\#$} & $\%$ \\
\hline Casual Cores & 7 & 0.3 \\
Chunks & 148 & 7.1 \\
Percussion Flakes & 658 & 31.7 \\
Flake Shatter & 484 & 23.3 \\
Unidentified & 29 & 1.4 \\
Bipolar Cores & 39 & 1.9 \\
Scalar Cores & 127 & 6.1 \\
Bipolar Flakes & 369 & 17.8 \\
Bipolar Corner Flakes & 163 & 7.9 \\
Piece Esqueillees & 50 & 2.4 \\
\cline { 2 - 3 } TOTAL & 2074 & 100.0 \\
\hline
\end{tabular}

A distinction should also be made between bipolar cores (in the generic sense) and pièce esquillées or battered pieces. Pièce esquillées, as defined here, are characterized by opposing, battered edges but such pieces show no evidence of major flake removals. Brian Hayden has recently clarified the similarities and differences between bipolar cores and pièce esquillées (1980). The distinctions used here follow closely the polythetic attribute sets which he outlines.

Other characteristic artifacts of bipolar industries are special flakes which spall off the corners of a scalar core in burin-like fashion. They are rectangular in plain view and generally triangular in transverse cross-section. These were not classified as bipolar flakes because they are sufficiently frequent to merit a separate category. In many instances these bipolar corner flakes are fragments of transversally split bipolar cores. When a small scalar core splits two rectangular corner flakes result. Bipolar corner flakes are illustrated in Figure 4C.

The three miscellaneous categories shown in Figure 2 are flake shatter, chunks, and unidentified pieces. These artifacts are pictured in Figure 3D. As explained above, fragments of flakes (usually the distal portions) lacking bulbs of force are classified as flake shatter. 
(Fragmentary flakes which retain the bulb are considered flaker). Chunks include fragments of percussion cores and core shatter from such cores. The few obsidian fragments which were unidentified could probably be classified in one or another of Boksenbaum's smash flake categories (1980).

The final category is that of spalls. Evidence detailed below indicates that most obsidian was brought into Paso de la Amada in the form of small spalls (see Figure 5). The term spall refers to large flakes, large flake fragments, or chunks. "Spall" is used in preference to these other terms to avoid confusion such as would arise from describing flakes removed from larger flakes. Also, the term "flake" suggests more technological finesse and purposive preforming thant is evidenced in the imported spalls. It appears that nodules of obsidian were unskillfully broken or shattered at the source area and that the best large flat pieces or spalls were selected for use or export.

\section{Fabricators}

Many possible fabricating tools used in the obsidian industry were recovered in the excavations at Paso de la Amada. These consist of hammerstones and anvils. The criteria for identifying hammerstones was their battered protuberances. In the case of hammerstones, it is not presently possible to determine whether they were used to knap obsidian or for other purposes such as shaping "ground" stone tools by a pecking process. As can be seen in Figure 6 there are hammerstones of numerous sizes in the Paso de la Amada collection. Based upon experience replicating the artifact types described above, it is the author's view that the smaller hammerstones would have been preferred in knapping the small cores or spalls which were imported into Paso de la Amada. All hammerstones from Paso de la Amada are of hard stone such as quartzite.

Anvils are less numerous than hammerstones. The identifying characteristic of anvils is pitting in the form of a small, shallow depression in the middle of a flat surface. Pitting is caused by the penetration of the distal end of a bipolar core into the anvil. The two anvils pictured in Figure 7 are of a hard metamorphic stone. Both of these anvils were also used as hammerstones, probably for obsidain.

In several replication experiments of bipolar industries the hammerstones used also became pitted. In the case of discoidal hammerstones this resulted in a notched stone which resembled a large cookie with a small bite taken out. No such hammerstones were noted in the Paso 
de la Amada collection. They are mentioned here in the chance that such tools may be recovered at other Early Preclassic sites.

\section{Techniques}

The two rudimentary flaking techniques evidenced in the artifacts described above were direct percussion and bipolar percussion. Neither technique was well developed and could have been done by most anyone with no prior experience or knowledge.

The peculiarity of the Early Preclassic direct percussion technique is that the percussion blow was perpendicular to the plane surface of the spall from which flakes were being removed. The hammerstones employed were small cobbles of hard metamorphic stone such as quartzite (see Figure 6). This technique resulted in the characteristic flake form which was described previously.

The bipclar technique has been well described in the ethnographic present (see White, 1968). With this technique both a hammerstone and an anvil support are used. The core to be flaked is placed upon the anvil and a blow struck into the obsidian at a $90^{\circ}$ angle to the plane surface of the anvil (see Figure 8). A bipolar flake is removed when a blow of sufficient force is delivered. Sometimes the flake is the same length as the bipolar core as evidenced in crushing at both the proximal and distal ends of some flakes. Bipolar flakes of this description are present in the Paso de la Amada collection. The hammerstones used prehistorically with this technique were the same described above; however, anvils were of a comparatively "softer" stone such as schist.

The data in Table 1 clearly demonstrate that the emphasis at Paso de la Amada was on the production of percussion flakes and to a lesser extent bipolar flakes. In the industry as it has been explicated small percussion cores were reduced by a bipolar method after they were too small to be flaked effectively by handheld (?) percussion. The bipolar technique is a logical and oft employed way to extract more flakes from otherwise unusable pieces of stone (cf. White, 1977).

Evidence supporting the structure of the industry as it has been presented above is seen in the frequency of identifiable casual cores in relation to other artifacts. Only 20 casual cores were identified in a collection of 16627 pieces, or 0.1 percent of the collection. This translates into 831.4 flakes, chunks, etc., per whole core. Even con. siderating the core shatter and partial cores subsumed in the "chunk" category the discrepancy in the number of flakes removed from each 


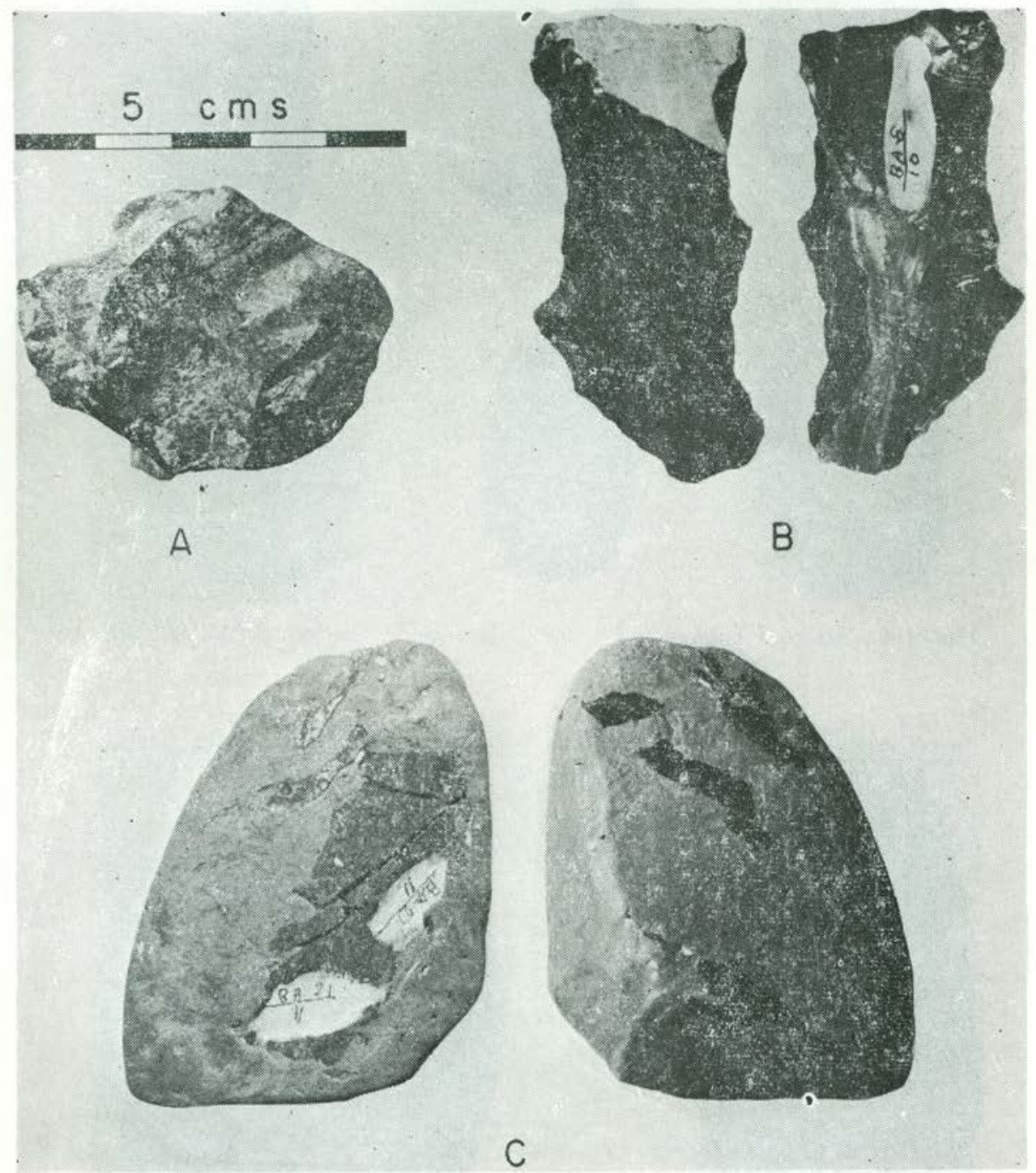

Figure 5. Obsidian commodities imported into Paso de la Amada. A-Small nodule of raw material; B-Dorsal and ventral views of a spall fragment; $\mathrm{C}$-Dorsal and ventral views of reconstructed spall.

Estudios de Cultura Maya. Vol. XIII, 1981

Instituto de Investigaciones Filológicas/

Centro de Estudios Mayas, UNAM 


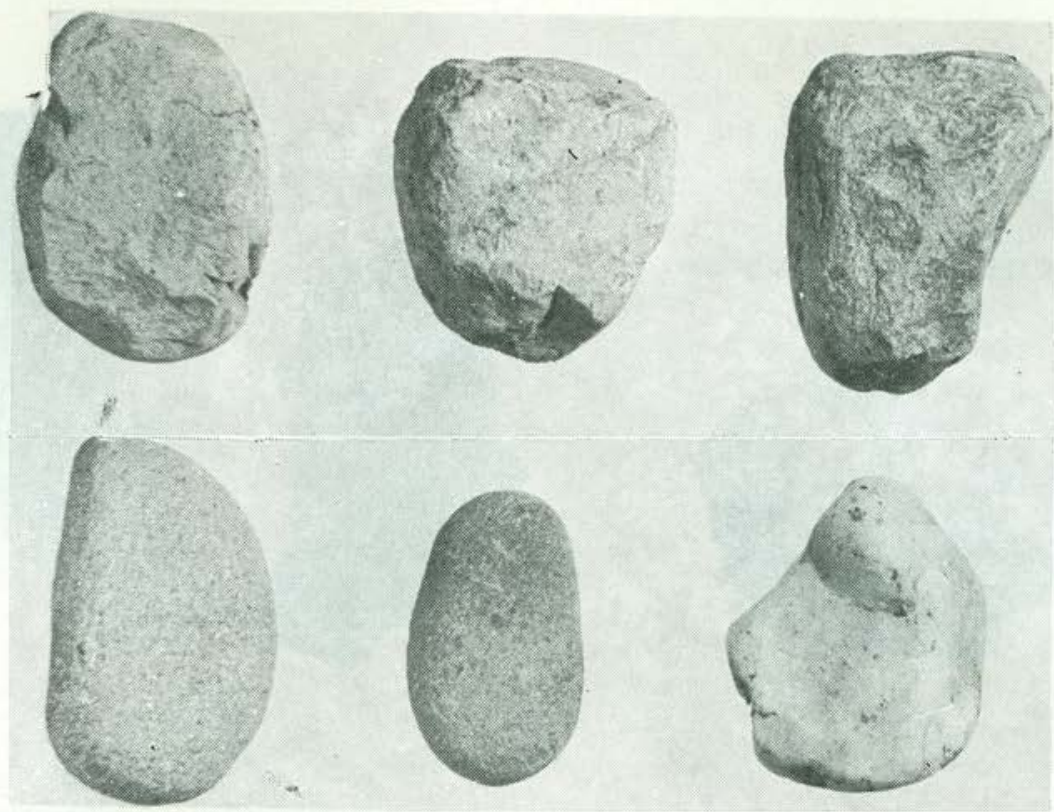

Figure 6. Assorted hammerstones from Paso de la Amada. Scale half size.

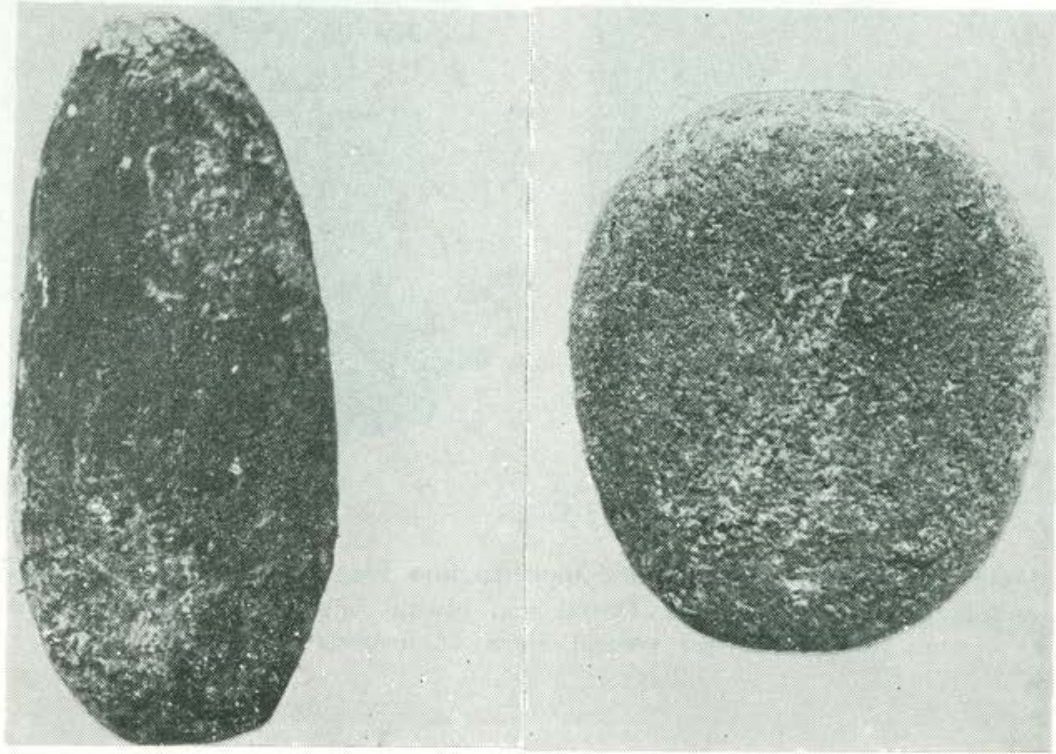

Figure 7. Two anvils showing the pitting resulting from bipolar flaking. Scale full size. 


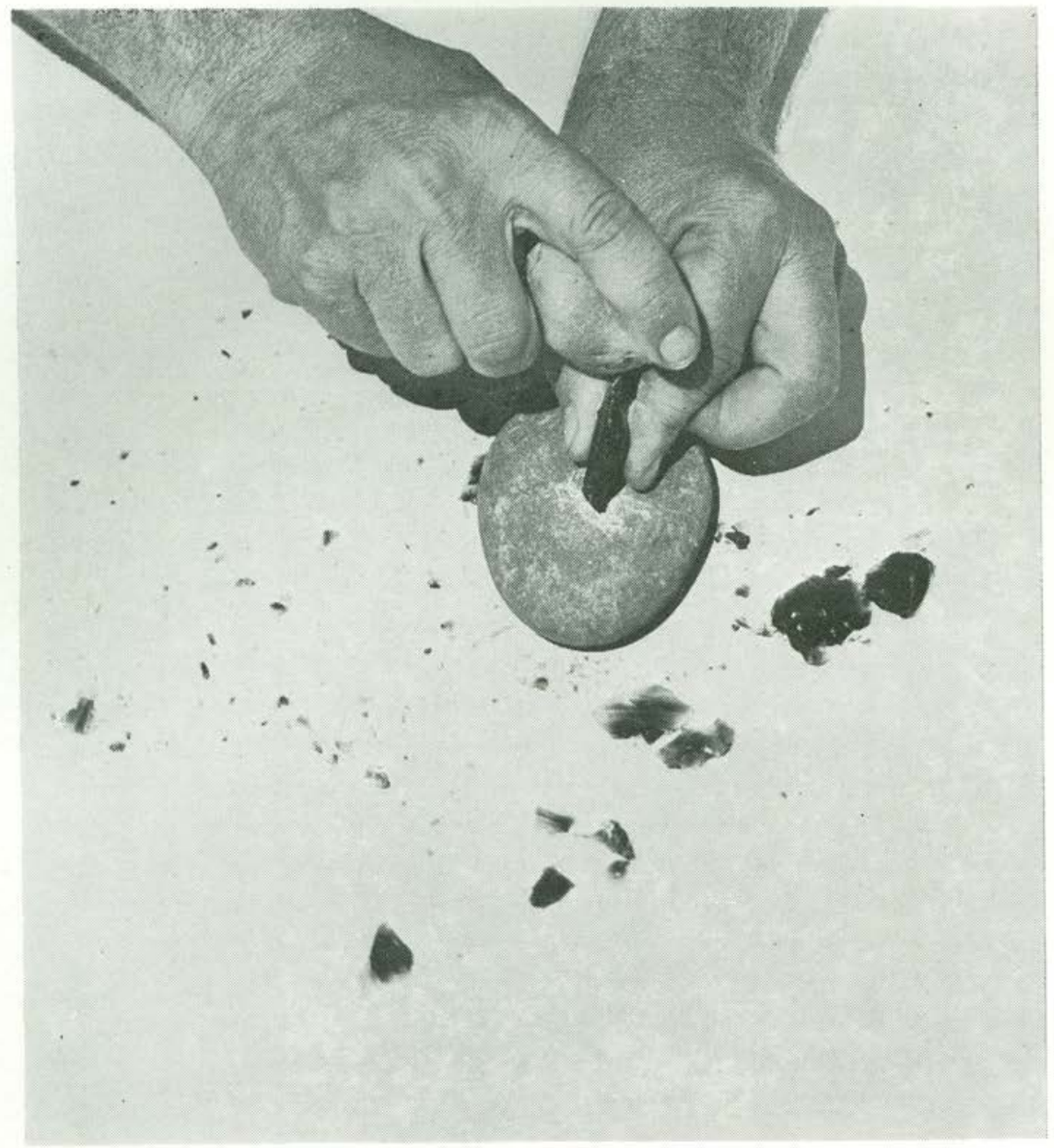

Figure 8. Closeup of the bipolar technique showing the relationships between the anvil, bipolar core, and hammerstone during the process of manufacture.

Estudios de Cultura Maya. Vol. XIII, 1981

Instituto de Investigaciones Filológicas/

Centro de Estudios Mayas, UNAM

http://www.iifilologicas.unam.mx/estculmaya/ 
core is significantly more than would be expected for the small spalls imported into Paso de la Amada. The reconstructed core-spall shown in Figure 5 revealed that approximately $30-40$ flakes were removed before the casual core was discarded. This low estimate has been confirmed experimentally.

The easy solution to this discrepancy is to assume that exhausted casual cores were reduced further (and thereby "destroyed") with the bipolar technique. Of special interest is that 8 percent of the 2074 pieces in the sample were bipolar and scalar cores-especially consid. ering that only 0.1 percent were casual cores. Furthermore, each bipolar core averaged only 3.2 flakes each. This indicates the small size of the bipolar cores at the beginning of reduction which is explained by using waste products from the percussion process; namely, expended cores, chunks, and large flakes. Complementary evidence of this interpretation is found on some of the bipolar cores which display definite percussion flake scars.

Percussion produced flakes and associated debitage at Paso de la Amada are significantly higher than the bipolar producst. This probably does not mean that percussion flaking was culturally more important or required more skill but rather may be more indicative of the original size of most spalls and of the transition point at which a casual core was reduced by a bipolar technique. Viewed diachronically there is a slight shift between the Barra and Ocos phases to a greater emphasis or reliance on bipolar percussion during the Ocos phase. Rather than see this as changing techniques it is more likely evidence that obsidian had become relatively more scarce (or that incoming spalls were smaller). Since the techniques of direct percussion and bipolar percussion are so simple it is doubtful that the slight variation between them signals changing levels of craftsmanship. A changing emphasis could, however, reflect economic changes such as conservation, observable through the increase of bipolar percussion-the hypothesis being that it is a method especially suited to extracting more tools (usuable flakes) from an otherwise worthless stone (White, 1977). However, the sample of Barra phase obsidian is still too small for valid comparisons.

\section{Commodities}

Reconstruction of the form of imported obsidian or obsidian commodities is based upon an analysis of artifact types, frequencies, and special artifact attributes. The size of the largest flakes and chunks, 
flake angles, primary flake dorsal surfaces, and cortex percentages indicate that the most common imported form of obsidian was a thick, tabular spall with several acute, angled edges. Size variation of the largest flakes and cores per obsidian source* are shown in Table 2. The obvious conclusion is that the incoming spalls were relatively small -perhaps $10 \times 10 \mathrm{~cm}$. and $4 \mathrm{~cm}$. thick. On the other hand, the metric data for bipolar cores denotes a beginning size of $4 \times 3 \times 2$ $\mathrm{cm}$. or approximately 10 percent of the size of imported spalls. The low cortex ratio also implies that raw material was not brought in (except occasionally from the Tajumulco source). The author's ex. periments demonstrate that a small nodule of raw material should yield approximately 50 percent cortex on the resultant flakes and debitage. Further evidence for incoming spalls is found on some large percussion flakes. The first flakes removed from the spall core are conch-shaped and have no dorsal ridges because they intersected a flat surface (see Figure 3B). This was the ventral surface of a large spall. Flake angles vary from $50-65^{\circ}$ (using Wilmsen's (1968) method of measuring flake angles). This suggests a spall with "prism-like" edges.

Independent confirmation for a model of imported spalls was obtained by reconstructing a spall from percussion flakes, flake shatter and an exhausted casual core. This is shown in Figure 5. Also, evidence of the flake removal sequence obtained from this reconstruction demonstrated a lack of a definite flaking pattern or that any specialized flake form was being produced. Flakes were removed from the most convenient edge in the most convenient manner.

The fact that it was possible to reconstruct a spall also indicates workshop debris which is relatively undisturbed. Workshop debris as well as fabricating tools were found in association with several structures at Paso de la Amada. The simple techniques and fabricators involved would suggest that anyone could produce their own obsidian flakes. This coupled with their deposition in or near all sampled domestic units implies a non-specialized domestic industry conceivably within the cultural repertoire of the common man.

Analysis of obsidian sources revealed that obsidian was obtained from three different locations in Guatemala. These are the nearby Tajamulco source and the more distant San Martín Jilotepeque and El Chayal sources near present-day Guatemala City. These data are described in detail elsewhere (Clark and Lee, n. d.). 


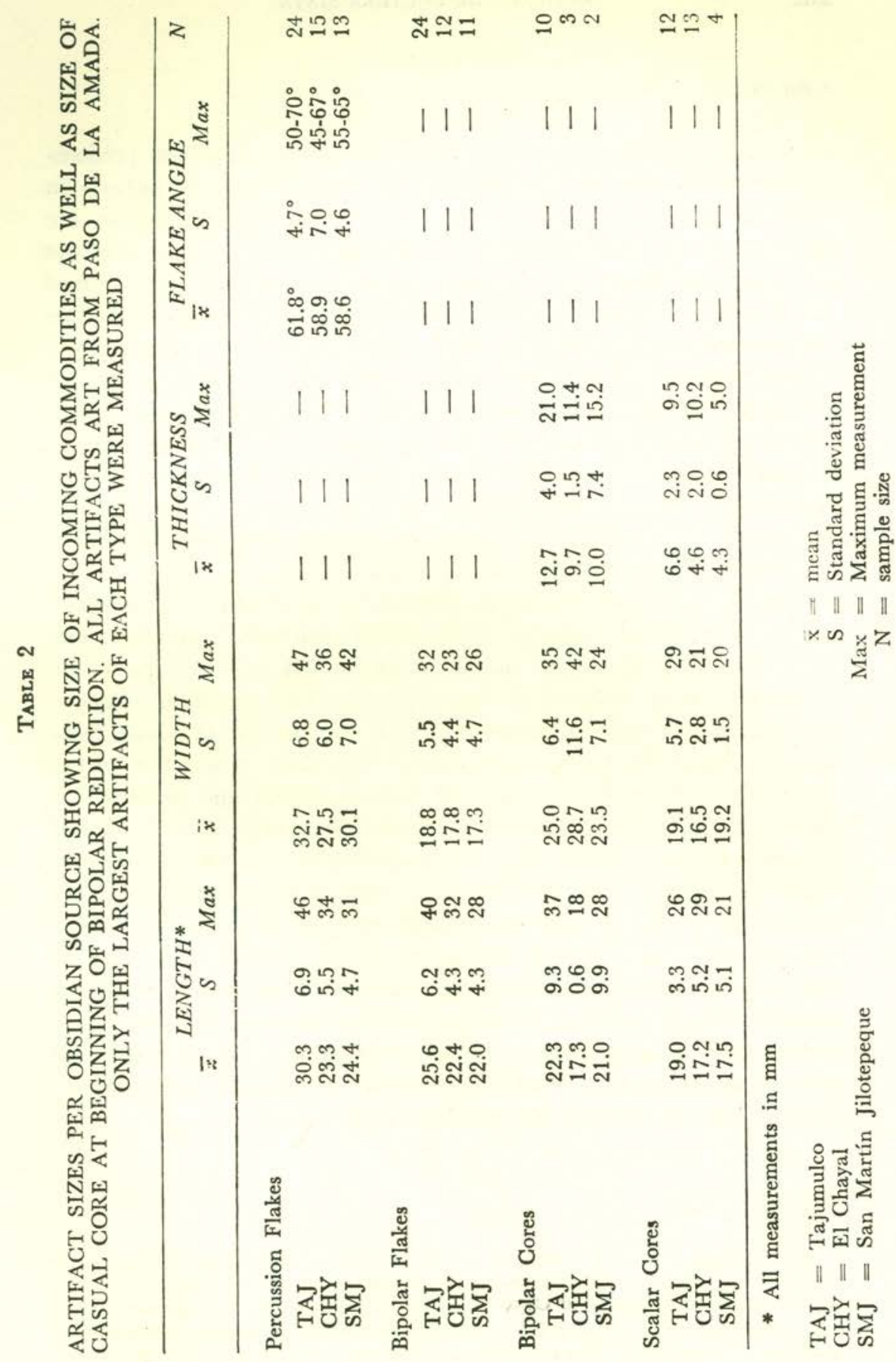

Estudios de Cultura Maya. Vol. XIII, 1981

Instituto de Investigaciones Filológicas/

Centro de Estudios Mayas, UNAM

http://www.iifilologicas.unam.mx/estculmaya/ 


\section{Conclusions}

Present evidence shows that flake, not blade, industries predominated during the Early Preclassic or Early Formative periods in much of Mesoamerica; however, the extent of these industries has yet to be determined. One such industry from Paso de la Amada was described and shown to be extremely simple. Artifacts were defined and characterized in behavioral terms and their place in the Early Preclassic industry shown schematically. The simplicity of the industry is a true reflection of the non-specialized nature of the knapping techniques used at Paso de la Amada. Only two rudimentary percussion techniques were in use, either of which could have been performed by almost anyone without prior knowledge of flaking stone. This implies a domestic, non-specialized industry in which everyone produced their own tools. This is partially substantiated by the intrasite distribution of workshop debris and fabricating tools.

Analysis of artifact types and frequencies permitted a plausible interpretation of the form(s) of imported obsidian. Imported commodities were surprisingly simple being limited to small spalls and occasional small nodules of raw material. This situation changed dramatically in subsequent periods with the advent of blade technology. Numerous papers have shown that blade production was a specialized industry which required consumate skill and practice (cf. Crabtree, 1968). The change from flake industries to blade industries therefore marks a change from a non-specialized to a specialized craft. Consequently, the transition from flake technology to blade technology also marks a critical step in development of craft specialization and the economy and should be given more consideration than it has thus far received. Perhaps the major problem has been one of classification. Hopefully, the artifact types illustrated and described herein and by Boksenbaum (1980) will facilitate later studies of such collections so that eventually detailed regional and areal comparisons, which are presently impossible, can be made.

\section{Acknowledgements}

The obsidian collection from Paso de la Amada resulted from research sponsored by the New World Archaeological Foundation and directed by Gareth W. Lowe and Jorge Fausto Ceja T. I extend thanks to them for allowing me to study the collection. I also gratefully acknowledge the inimitable photographic services of Douglas D. Bryant and map-making abilities of Kristi Butterwick in providing the illustrations for this paper. 


\section{BIBLIOGRAPHY}

Boksenbaum, Martin W.

1978 Lithic Technology in the Basin of Mexico During the Early and Middle Preclassic. Unpublished Ph. D. dissertation, The City University of New York.

1980 "Basic Mesoamerican Stone-Working: Nodule Smeshing?" Lithic Technology, Vol. IX, No. 1.

Ceja, Jorge Fausto

1978 Paso de la Amada (un sitio del Preclásico temprano en el Soconusco). Tesis profesional, Universidad Veracruzana. Xalapa, Veracruz.

Clark, John E. and Thomas A. Lee, Jr.

n. d. "Reciprocity, Redistribution and Preclassic Obsidian Exchange in Chiapas, Mexico". To be published in Exchange in Early Mesoamerica, Kenneth Hirth (ed.).

Cobean, R. H.; M. D. Coe; E. A. Perry, JR.;

K. K. Turekian, and D. P. Kharkar

1971 "Obsidian Trade at San Lorenzo Tenochtitlan, Mexico". Science, Vol. 174, pp. 666-71.

Coe, Michael D.

1961 La Victoria, an Early Site on the Pacific Coast of Guatemala. Papers of the Peabody Museum of Archaeology and Ethnology, Harvard University, Vol. 53. Cambridge.

Coe, M. and K. Flannery

1967 Early Cultures and Human Ecology in South Coastal Guatemala. Smithsonian Press. Washington.

Collins, Mighael B.

1975 "Lithic Technology as a Means of Processual Inference". Lithic Technology: Making and Using Stone Tools, Earl Swanson (ed.).

Crabtree, Don E. Mouton Publishers, The Hague.

1968 "Mesoamerican Polyhedral Cores and Prismatic Blades". American Antiquity, Vol. 33, pp. 446-78.

1972 An Introduction to Flint Working. Idaho State University Museum, Pocatello.

Davis, Dave D.

1975 "Patterns of Early Formative Subsistence in Southern Mesoamerica 1500-1000 B. C." Man, Vol. 10, No. 1, pp. 41-59.

Green, Dee F. and Gareth W. Lowe

1967 Altamira and Padre Piedra, Early Preclassic Sites in Chiapas, Mexico. Papers of the New World Archaeological Foundation, No. 20. Provo.

Grove, David C.

1971 Archaeological Investigations Along the Rio Cuautla, Morelos 1969 and 1970. Informe submitted to the Instituto Nacional de Antropología e Historia, México.

HAYDEN, BRIAN

1980 "Confusion in the Bipolar World: Bashed Pebbles and Splintered Pieces". Lithic Technology, Vol. IX, No. 1.

Lowe, Gareth W.

1975 The Early Preclassic Barra Phase of Altamira, Chiapas: A Review with New Data. Papers of the New World Archaeological Foundation, No. 38. Provo. 
1978 "Eastern Mesoamerica". In Chronologies in New World Archaeology, Academic Press, Inc., New York.

MacNeish, Righard S.; Antoinette Nelken-Terner

and Irmgard Weitlaner de Johnson

1967 The Prehistory of the Tehuacan Valley. The Nonceramic Artifacts, Vol. 2. University of Texas Press, Austin.

Mirambell, Lorena

1974 "Materiales líticos arqueológicos: generalidades". Cuadernos de Trabajo No. 4 del INAH, Departamento de Prehistoria.

Niederberger, Christine

1976 Zohapilco: cinco milenios de ocupación humana en un sitio lacustre de la cuenca de México, No. 30. Departamento de Prehistoria, Colección Científica. Serie Arqueología. INAH. México.

Pires, Ferreira, Jane W.

1976 "Obsidian Exchange in Formative Mesoamerica". The Early Mesoamerican Village, Kent V. Flannery (ed.). Academic Press, New York.

Sheets, Payson D.

1975 "Behavioral Analysis and the Structure of a Prehistoric Industry". Current Anthropology, Vol. 16, pp. 369-91.

Tolstoy, Paul

1971 "Utilitarian Artifacts of Central Mexico". Handbook of Middle American Indians, Vol. 10, pp. 270-96. University of Texas

White, J. Peter Press, Austin.

1968 "Fabricators, Outils escailles or Scalar Cores?" Mankind, Vol. 16 , No. 12 , pp. 658-66.

1977 Reply to "The Myth of Bipolar Flaking Industries", de L. W. Patterson and J. B. Sollberger. Nezwsletter of Lithic Technology,

WILMSEN, EdWin N. Vol. V, No. 3, p. 40, 1976.

1968 "Lithic Analysis in Paleoanthropology". Science, Vol. 161, No. 6, pp. 982-87.

Zeitland, RoBert N.

1978 "Long-distance Exchange and the Growth of a Regional Center: An Example from the Southern Isthmus of Tehuantepec, México". Prehistoric Coastal Adaptations, Barbara L. Stark and Barbara Voorhies (eds.). Academic Press, New York.

1979 Prehistoric Long-Distance Exchange on the Southern Isthmus of Tehuantepec. Unpublished Ph. D. dissertation. Yale University, New Haven. 